\title{
2-Thiabicyclo[3.2.0]hepta-3,6-dienes. 2. Thermal and Photochemical Isomerization of 2-Thiabicyclo[3.2.0]hepta-3,6-dienes. An Example of the Antarafacial-Antarafacial Cope Rearrangement
}

\author{
Richard H. Hall, Herman J. den Hertog, Jr., and David N. Reinhoudt* \\ Laboratory of Organic Chemistry, Twente University of Technology, Enschede, The Netherlands
}

Received June 30, 1981

\begin{abstract}
Thermal rearrangement of 2-thiabicyclo[3.2.0]hepta-3,6-diene-6,7-dicarbonitriles 1-3 to their 4,5-dicarbonitrile isomers 4-6 takes place at $110-140^{\circ} \mathrm{C}$ in yields of $82-84 \%$. The reactions are first order with rates almost independent of the polarity of the solvent. Activation parameters $\left(\Delta H^{\ddagger}=120-140 \mathrm{~kJ} \mathrm{~mol}^{-1}\right.$ and $\Delta S^{\ddagger} \approx 0 \mathrm{~J} \mathrm{~K}^{-1}$ $\mathrm{mol}^{-1}$ ) are in agreement with a concerted symmetry-allowed antarafacial-antarafacial Cope rearrangement. Compounds 1-3 rearrange photochemically via cleavage of the C-1-S bond to the 1,7-dicarbonitrile isomers 7-9. Isomer 9 rearranges further on prolonged irradiation to give 10. A tentative mechanism for this rearrangement is given.
\end{abstract}

The synthesis of 2-thiabicyclo[3.2.0]hepta-3,6-dienes (e.g., 1), potential precursors of thiepins, has been described in the preceding paper. ${ }^{1}$ This paper deals with the thermal and photochemical isomerization of these compounds. ${ }^{2,3}$ The thermal isomerization of 1 is not only of importance as a possible route to thiepins but also from a mechanistic point of view because the thermal isomerization of bicyclo[3.2.0]hepta-3,6-dienes has been the subject of controversy.

It has been suggested that the thermal rearrangement of bicyclo[3.2.0] hepta-3,6-dien-2-ones ${ }^{5}$ represents the first example of an antarafacial-antarafacial Cope rearrangement, a mode of rearrangement which usually will not take place for the less rigid analogous acyclic 1,5-hexadienes because of a highly strained transition state. However, the rearrangement of the bicyclo[3.2.0]hepta-3,6-dien-2-ones ${ }^{5}$ is unselective and is accompanied by formation of the analogous monocyclic tropones. ${ }^{5}$ Moreover, alternative mechanisms for this type of rearrangement have been advanced. ${ }^{6,7}$ Baldwin and Kaplan ${ }^{6}$ have proposed the intermediacy of cis,trans,cis-cycloheptatriene species which can subsequently recyclize to give the isomeric bicyclo[3.2.0] hepta-3,6-diene-2-ones or isomerize to give tropones. Fráter et al. ${ }^{7}$ have put forward a further possibility, viz., two consecutive symmetry-allowed antarafacial-suprafacial $[1,3]$ sigmatropic reactions and bicyclo[4.1.0]-heptadienone intermediates, to account for the rearrangement.

Photochemical rearrangement of bicyclo[3.2.0]hepta3,6-diene derivatives was reported by Eaton ${ }^{8}$ and by Chapman and Lassila. ${ }^{9}$ This type of rearrangement has also been described for 2a,7b-dihydrocyclobuta[b][1]benzothiophenes both in intermolecular photochemical $[2$ +2 ] cycloaddition reactions of benzo[b]thiophenes and acetylenes ${ }^{10,11}$ and in intramolecular photochemical [2+

(1) Part 1: Hall, R. H.; den Hertog, H. J., Jr.; Reinhoudt, D. N. J. Org. Chem., preceeding paper in this issue.

(2) Preliminary results have been published; see: Reinhoudt, D. N.; Volger, H. C.; Kouwenhoven, C. G.; Wynberg, H.; Helder, R. Tetrahedron Lett. 1972, 5269.

(3) The intial results of this work are partially also described in a thesis: Helder, R. Thesis, Groningen University, 1974.

(4) Woodward, R. B.; Hoffmann, R. "The Conservation of Orbital Symmetry"; Academic Press: New York, 1970.

(5) Miyashi, T; Nitta, M; Mukai, T. J. Am. Chem. Soc. 1971, 93, 3441

Kimura, M.; Mukai, T. Tetrahedron Lett. 1970, 4207.

(6) Baldwin, J. E.; Kaplan, M. S. J. Am. Chem. Soc. 1971, 93, 3969.

Baldwin, J. E.; Kaplan, M. S. Ibid. 1972, 94, 668.

(7) Fräter, G.; Habich, A.; Hansen, H.-J.; Schmid, H. Helv. Chim. Acta $1969,52,335$.

(8) Eaton, P. E. Tetrahedron Lett. 1964, 3695

(9) Chapman, O. L.; Lassila, J. D. J. Am. Chem. Soc. 1968, 90, 2449.
Chart I
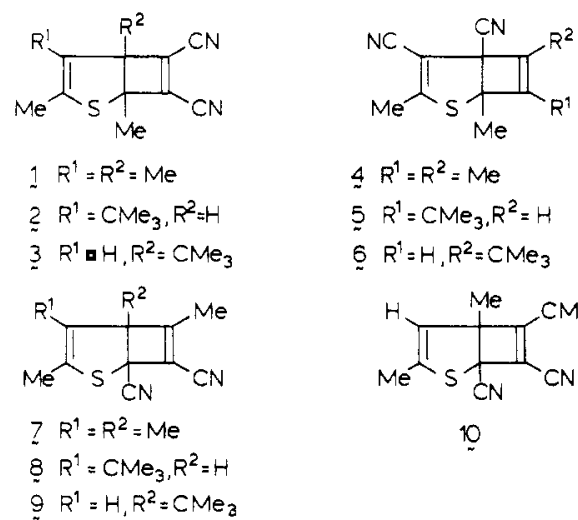

$4 R^{1}=R^{2}=M e$

$5 \mathrm{R}^{1}=\mathrm{CMe}_{3}, \mathrm{R}^{2}=\mathrm{H}$

$\underset{\sim}{6} R^{1}=H_{1} R^{2}=\mathrm{CMe}_{3}$

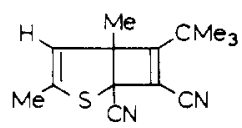

10

2] cycloaddition reactions of 1-benzothiepins. . $^{10,12,13}$ Recently a similar rearrangement has been postulated to account for the desulfurated photoproducts of 3 benzoylthiophenes and dimethyl acetylenedicarboxylate (vide infra). ${ }^{14,15}$

\section{Results}

Thermal Rearrangement. When 1,3,4,5-tetramethyl-2-thiabicyclo[3.2.0] hepta-3,6-diene-6,7-dicarbonitrile $\left(1,{ }^{1}\right.$ Chart I) was heated in refluxing xylene $\left(140^{\circ} \mathrm{C}\right)$ for $18 \mathrm{~h}$, a colorless crystalline compound was obtained in a yield of $82 \%$. Elemental analysis $\left(\mathrm{C}_{12} \mathrm{H}_{12} \mathrm{~N}_{2} \mathrm{~S}\right)$ and mass spectrometry $\left(\mathbf{M}^{+}, m / e\right.$ 216.072) showed that it was an isomer of 1 . When the compound was heated in refluxing tetraethyleneglycol dimethyl ether $\left(275^{\circ} \mathrm{C}\right)$ for $15 \mathrm{~min}$, 3,4,5,6-tetramethyl-1,2-benzenedicarbonitrile ${ }^{3,17,18}$ was ob-

(10) For a review on these reactions, see: Reinhoudt, D. N. Adv. Heterocycl. Chem. 1977, 21, 253.

(11) (a) Ditto, S. R.; Davis, P. D.; Neckers, D. C. Tetrahedron Lett. 1981, 521. (b) Tinnemans, A. H. A.; Neckers, D. C. J. Org. Chem. 1978, 43,2493 . (12)

(12) Reinhoudt, D. N.; Kouwenhoven, C. G. Tetrahedron 1974, 30 ,

(13) Hofmann, H.; Gaube, H. Justus Liebigs Ann. Chem. 1977, 1874

(14) Arnold, D. R.; Hadjiantoniou, C. P. Can. J. Chem 1978, 56, 1970.

(15) The same kind of rearrangement has been postulated earlier by Kuhn and Gollnick, ${ }^{18}$ but it is possible that in their case the resulting phthalate esters are formed by sulfur elimination from 1,4-addition products. The 2-thiabicyclo[3.2.0] hepta-3,6-dienes described in the present paper do not undergo sulfur extrusion upon irradiation under the conditions described, except possibly to a limited extent.

(16) Kuhn, H. J.; Gollnick, K. Chem. Ber. 1973, 106, 674.

(17) Full characterization of this compound is given in part 3 of this series: Hall, R. H.; et al. J. Org. Chem., accompanying paper in this issue.

(18) Suzuki, H.; Hanafusa, T. Synthesis 1974, 53 . 

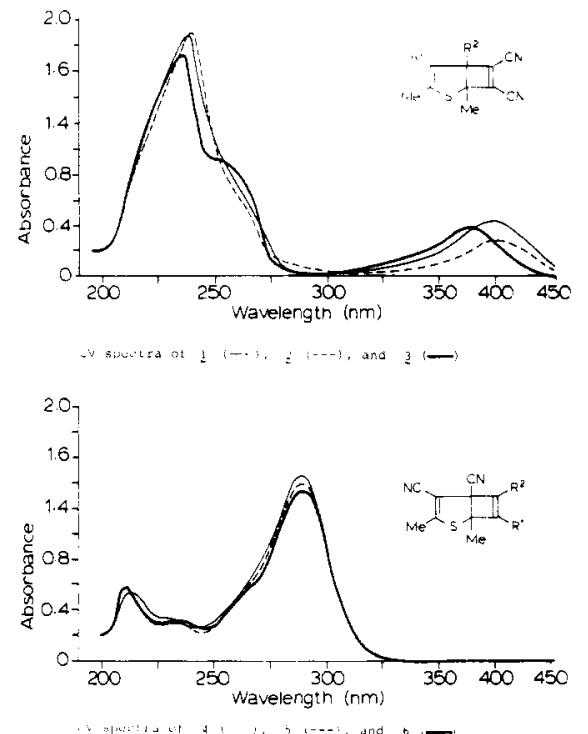

Figure 1. UV spectra of compounds 1-6: $1, \mathrm{R}^{1}=\mathrm{R}^{2}=\mathrm{Me} ; 2$, $\mathrm{R}^{1}=\mathrm{CMe}_{3}, \mathrm{R}^{2}=\mathrm{H} ; 3, \mathrm{R}^{1}=\mathrm{H}, \mathrm{R}^{2}=\mathrm{CMe}_{3} ; 4, \mathrm{R}^{1}=\mathrm{R}^{2}=\mathrm{Me} ; 5$, $\mathrm{R}^{1}=\mathrm{CMe}_{3}, \mathrm{R}^{2}=\mathrm{H} ; 6, \mathrm{R}^{1}=\mathrm{H}, \mathrm{R}^{2}=\mathrm{CMe}_{3}$.

tained, indicating that the two carbonitrile groups were still adjacent in the isomer. The ${ }^{13} \mathrm{C}$ NMR spectrum of the isomeric compound with four $\mathrm{C}_{\mathrm{sp}^{2}}$, two carbonitrile, and six $\mathrm{C}_{\mathrm{pp}^{3}}$ (four methyl) carbon resonances showed that the 2-thiabicyclo[3.2.0] hepta-3,6-diene structure had been preserved. Its ${ }^{1} \mathrm{H}$ NMR spectrum showed four distinct methyl resonances, two of which were weakly coupled homoallylically, indicating that the isomer is either 3,4or 6,7-dimethyl substituted. The main fragmentation pattern in its mass spectrum involved the loss of 2-butyne with consequent formation of a dimethylthiophenedicarbonitrile, indicating that the compound was a 6,7-dimethyl derivative. The four $\mathrm{C}_{\mathrm{sp}}$ resonances in its ${ }^{13} \mathrm{C}$ NMR spectrum ranged over $63.8 \mathrm{ppm}$, whereas those of 1 were ranged over only $7.2 \mathrm{ppm}$, clearly showing that the C-3,4 ethene moiety was not symmetrically substituted. Since the two carbonitrile groups must be adjacent, the only possible structure for the isomer is $1,3,6,7$-tetramethyl-2-thiabicyclo[3.2.0] hepta-3,6-diene-4,5-dicarbonitrile (4).

4-(1,1-Dimethylethyl)-1,3-dimethyl-2-thiabicyclo[3.2.0]hepta-3,6-diene-6,7-dicarbonitrile (2) ${ }^{1}$ was similarly isomerized to 7-(1,1-dimethylethyl)-1,3-dimethyl-2-thiabicyclo[3.2.0]hepta-3,6-diene-4,5-dicarbonitrile (5) in a yield of $84 \%$ whereas 5-(1,1-dimethylethyl)-1,3-dimethyl-2-thiabicyclo[3.2.0] hepta-3,6-diene-6,7-dicarbonitrile (3) ${ }^{1}$ was isomerized to 6 -(1,1-dimethylethyl)-1,3dimethyl-2-thiabicyclo[3.2.0] hepta-3,6-diene-4,5-dicarbonitrile (6) in only $4 \mathrm{~h}$ at $110^{\circ} \mathrm{C}$ with a yield of $83 \%$. Full characterizations of 4-6 are given in Table I. The 6,7dicyano-2-thiabicyclo[3.2.0]hepta-3,6-dienes 1-3 are all yellow crystalline compounds, showing absorption maxima in their UV spectra (EtOH) at $402(\epsilon 2040), 406(\epsilon 1870)$, and $377 \mathrm{~nm}(\epsilon 1860)$, respectively, corresponding to an intramolecular charge-transfer transition of the vinyl sulfide $\pi$-donor and the dicyanoethylene $\pi$-acceptor moieties in the compounds. ${ }^{1}$ This intramolecular charge-transfer interaction is absent in the colorless 4,5 dicyano isomers 4-6. The UV spectra of the 6,7-dicyano compounds 1-3 and their 4,5-dicyano isomers 4-6 are shown in Figure 1.

(19) The isomerization of 1 to 4 was also measured by using two other methods, ${ }^{1} \mathrm{H}$ NMR and HPLC analyses. The results are almost the same but less accurate (see Experimental Section).
The rates of the isomerizations of 1 to 4,2 to 5 , and 3 to 6 were measured by monitoring the change in absorbance, at the respective maxima, with time at various temperatures. The rearrangement of 1 into 4 was found to be first order for at least 3 half-lives in three different solvents: 1,3,5-trimethylbenzene, pentachloroethane, and dimethyl sulfoxide. Similarly, the rearrangements of 2 into 5 and 3 into 6 were found to be first order in pentachloroethane. A plot of $\log k$ vs. $T^{-1}$ gave the activation parameters of the isomerization reactions (Table II). For comparison, the rate of conversion of 1 to 4 was also measured by ${ }^{1} \mathrm{H}$ NMR spectroscopy and HPLC analysis. Both methods gave similar $k$ values $( \pm 10 \%)$, but these methods are less accurate. However, both methods have the advantage that the formation of 4 could experimentally be verified whereas the UV method only makes use of the disappearance of 1 .

Photochemical Reactions. When 1 was irradiated in ether $\left(\mathrm{N}_{2},-20^{\circ} \mathrm{C}, 8 \mathrm{~h}\right)$ with ultraviolet light, a colorless crystalline compound was obtained in a yield of $67 \%$. Elemental analysis $\left(\mathrm{C}_{12} \mathrm{H}_{12} \mathrm{~N}_{2} \mathrm{~S}\right)$, mass spectrometry $\left(\mathrm{M}^{+}\right.$, $m / e 216.072$ ), and its ${ }^{13} \mathrm{C}$ NMR spectrum (four $\mathrm{C}_{\mathrm{sp}}$, two carbonitrile, two $\mathrm{C}_{\mathrm{sp}}$, and four methyl carbon resonances) showed that it was a second isomeric 2-thiabicyclo[3.2.0]hepta-3,6-diene. Again, when this isomer was heated in refluxing tetramethylene glycol dimethyl ether $\left(275^{\circ} \mathrm{C}\right)$ for $15 \mathrm{~min}, 3,4,5,6$-tetramethyl-1,2-benzenedicarbonitrile ${ }^{3,17,18}$ was obtained, indicating that the two carbonitrile groups were adjacent in the isomer. Its ${ }^{1} \mathrm{H}$ NMR spectrum had four distinct methyl resonances, two of which were coupled homoallylically, indicating that the isomer was either 3,4- or 6,7-dimethyl substituted. The main fragmentation in its mass spectrum involved the loss of 2-butynenitrile with consequent formation of a trimethylthiophenecarbonitrile, and since the two carbonitrile groups must be adjacent, the isomer can only be either 3,4,5,6-tetramethyl-2-thiabicyclo[3.2.0] hepta-3,6-diene1,7-dicarbonitrile (7) or its 1,3,4,7-tetramethyl 5,6-dicarbonitrile isomer. However, its ${ }^{13} \mathrm{C}$ NMR spectrum clearly showed that it is 7 since in 4-6 C-5, with a carbonitrile substituent, resonates at $62.6-66.8 \mathrm{ppm}$, and the two $\mathrm{C}_{\mathrm{sp}^{3}}$ resonances of 7 are at 75.1 and $51.7 \mathrm{ppm}$ (see Table I). A full analysis of the spectral data (see Table I) confirms that the isomer is indeed 7.20

Similarly, irradiation of 2 gave 4-(1,1-dimethylethyl)3,6-dimethyl-2-thiabicyclo[3.2.0]hepta-3,6-diene-1,7-dicarbonitrile $(8)$ in a yield of $71 \%$ whereas irradiation under the same conditions of 3 gave 5-(1,1-dimethylethyl)-3,6dimethyl-2-thiabicyclo[3.2.0] hepta-3,6-diene-1,7-dicarbonitrile $(9,42 \%)$ and another isomer $(31 \%)$. On irradiation of 3 for only 1 h, 9 was obtained in $74 \%$ yield, and on irradiation of 9 for $8 \mathrm{~h}$, an approximately 50:50 mixture of 9 and the other isomer was obtained, showing that the second isomer most likely is a daughter product of 9 . The analytical and spectral data clearly showed that the compound was 6-(1,1-dimethylethyl)-3,5-dimethyl-2-thiabicyclo[3.2.0] hepta-3,6-diene-1,7-dicarbonitrile (10).

\section{Discussion}

The mechanism of the Cope rearrangement ${ }^{21}$ of 1,5 hexadienes has recently become the subject of controversy. The discussion is mainly concerned with whether the rearrangement takes place in a single step via a cyclic

(20) Helder ${ }^{3}$ tentatively assigned this structure, but its ${ }^{13} \mathrm{C}$ NMR data were not recorded.

(21) (a) Rhoads S. J. "Molecular Rearrangements"; de Mayo, P., Ed.; Interscience: New York, 1963; Part 1, p 655. (b) Rhoads, S. J.; Raulins, N. R. Org. React. 1975, 22, 1. 


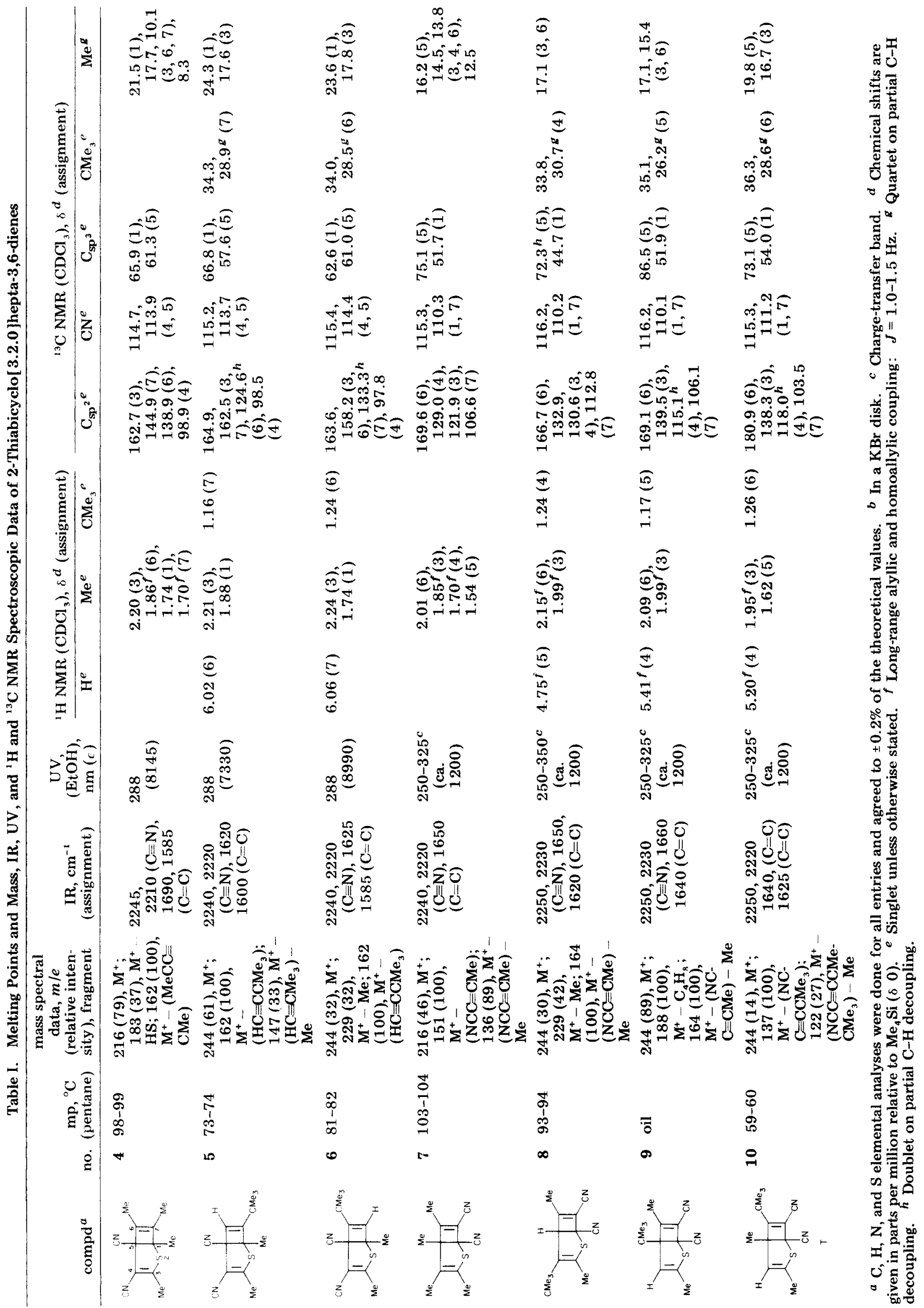


Table II. Rate Constants ${ }^{a}$ for Thermal Isomerization of 2-Thiabicyclo[3.2.0]hepta-3,6-dienes under Various Conditions

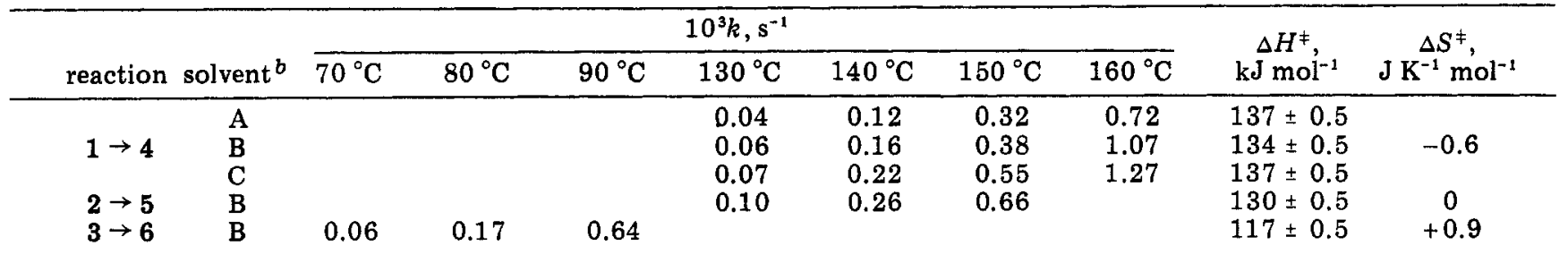

a Obtained by UV spectrometry (see Experimental Section). ${ }^{b} A=1,3,5$-trimethylbenzene, $B=$ pentachloroethane, and $\mathrm{C}=$ dimethyl sulfoxide.

transition state $e^{22}$ or whether the intermediate of the reaction is a 1,4-cyclohexylene biradical. ${ }^{23,24}$ Further, whereas the vast majority of Cope rearrangements, if concerted, are regarded to be suprafacial-suprafacial $[3,3]$ sigmatropic processes with chairlike or, less commonly, boatlike transition states, Woodward and Hoffmann have predicted $^{4}$ that the rearrangement can also proceed in an antarafacial-antarafacial mode via a twistlike transition state. However, such processes will not normally be competitive because of the steric strain involved ${ }^{7}$ and, to our knowledge, have never been unambiguously proven to occur. We believe that the results described here of the thermal rearrangement of 6,7-dicyano-2-thiabicyclo[3.2.0]hepta-3,6-dienes can be regarded as being the first unambiguously established example of a Cope rearrangement proceeding in such an antarafacial-antarafacial manner.

It can clearly be seen that the activation energy is nearly independent of the solvent polarity, as it should be in a concerted reaction, and that the activation energy values of $120-140 \mathrm{~kJ} \mathrm{~mol}^{-1}$ are comparable to those reported for the Cope rearrangements of simple 1,5-hexadienes. ${ }^{23,24,27}$ The faster rate of the rearrangement compared to the rate of rearrangement of simple 1,5-hexadienes is readily explained by the different activation entropies involved: +0.9 to -0.6 compared with -55 to $-60 \mathrm{~J} \mathrm{~K}^{-1} \mathrm{~mol}^{-1} .{ }^{23 a, 26}$ The enhancement of the rate of isomerization of 3 to $6 \mathrm{com}$ pared to that of 2 to 5 must result from the presence of the tert-butyl group at the bridgehead (C-5) of 3. Presumably, the tert-butyl group in 3 weakens the C-1,C-5 bond and changes the conformation of the molecule. This change in conformation is reflected in the lower absorption maximum $(377 \mathrm{~nm})$ for the charge-transfer transition.

The low activation entropy of these rearrangements indicates that there is hardly any increase in strain in the transition state compared with that in the ground state (Scheme I, a). Alternative mechanisms that would also rationalize these isomerization reactions, which were proposed by Fráter et al. ${ }^{7}$ and Baldwin and Kaplan ${ }^{6}$ for similar reactions of bicyclo[3.2.0]hepta-3,6-diene and -hepta-3,6dien-2-one systems, are two consecutive symmetry-allowed antarafacial-suprafacial [1,3] sigmatropic reactions via a thianorcaradiene intermediate (Scheme I, b) or a symmetry-allowed ring opening of the cyclobutene ring to give a cis,trans,cis-1-thiacycloheptatriene (Scheme I, c) that subsequently recyclizes.

(22) (a) Marvell, E. N.; Li, T. H.-C. J. Am. Chem. Soc. 1978, 100, 883. (b) Gajewski, J. J.; Conrad, N. D. Ibid. 1978, 100,6268.

(23) (a) Wehrli, R. Schmid H. Bellus, D. Hansen, T.-J, Helv Chim. Acta 1977, 60, 1325. (b) Dewar, M. J. S.; Wade, L. E., Jr. J. Am. Chem. Soc. 1977, 99, 4417.

(24) In some cases, when the termini of the Cope system bear strongly dipolar stabilizing substituents, the reaction can take place via a 1,4-dipolar intermediate, ${ }^{26}$ which has been captured by such 1,4-dipolarophiles as acrylonitrile and benzaldehyde.

(25) Gompper, R.; Ulrich, W.-R. Angew. Chem. 1976, 88, 298.

(26) Frey, H. M.; Solly, R. K. Trans. Faraday Soc. 1968, 64, 1858

(27) Gajewski, J. J. J. Am. Chem. Soc. 1979, 101, 4393.
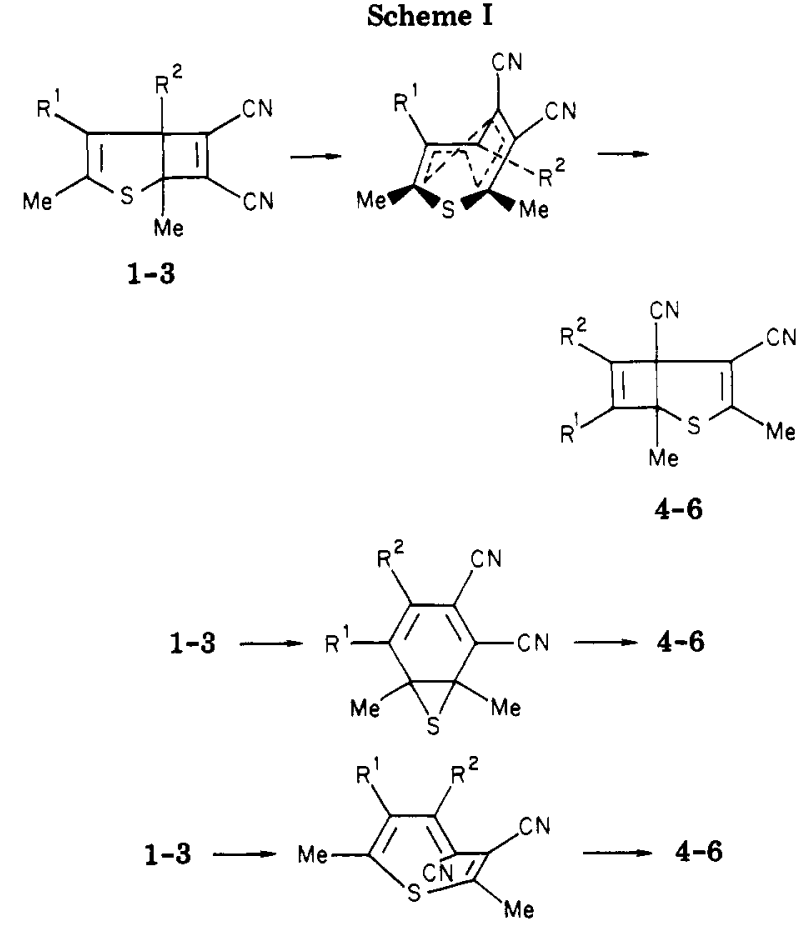

In the case of bicyclo[3.2.0] hepta-3,6-dien-2-ones, path $\mathrm{b}$ is difficult to exclude because there is no experimental evidence that would eliminate a bicyclo[4.1.0] heptadienone as a possible intermediate. However, in our case the intermediacy of a thianorcaradiene (path b) can be ruled out because Vogel et al. ${ }^{28}$ have shown that even at room temperature such compounds eliminate sulfur rapidly.

The other alternative (path c) proposed by Baldwin and $K_{\text {aplan }}{ }^{6}$ proceeding via the ring opening of the cyclobutene ring is rather unlikely. Branton et al. ${ }^{29}$ have studied the isomerization of bicyclo[3.2.0]hept-6-ene and found an activation energy of $193 \mathrm{~kJ} \mathrm{~mol}^{-1}$ which is at least $42-63$ $\mathrm{kJ} \mathrm{mol}^{-1}$ higher than that of a symmetry-allowed conrotatory ring opening of a monocyclic cyclobutene.

We conclude therefore that the thermal isomerization of 2-thiabicyclo[3.2.0] hepta-3,6-dienes 1-3 represents the first experimental confirmation that the prediction of Woodward and Hoffman, ${ }^{4}$ i.e., that antarafacial-antarafacial Cope rearrangements are possible, is correct.

Qualitative frontier orbital considerations explain why the rearrangements of 1-3 to 4-6 take place. One way to treat the Cope rearrangement is to regard the reaction as a $[4+2]$ cycloaddition with the C- $6, \mathrm{C}-7$ double bond as the 2- $\pi$-electron component and the C-1, C-5 $\sigma$ bond and the other $\pi$ bond as a four-electron component. ${ }^{30}$ Since

(28) Vogel, E.; Schmidbauer, E.; Altenbach, H.-J. Angew. Chem 1974, 86,818 .

(29) Branton, G. R.; Frey, H. M.; Montague, D. C.; Stevens, I. D. R. Trans. Faraday Soc. 1966, 62, 659.

(30) Fleming, I. "Frontier Orbitals and Organic Chemical Reactions"; Wiley: London, 1976; p 101. 


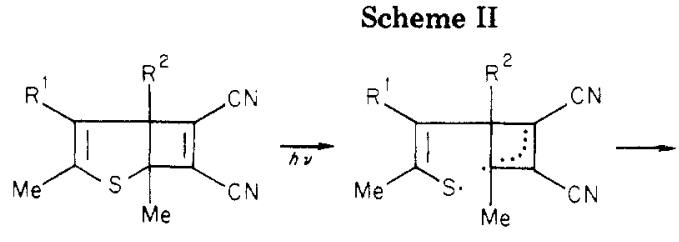

$1-3$

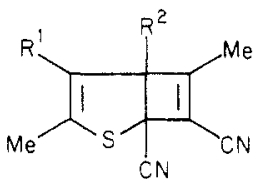

$7-9$

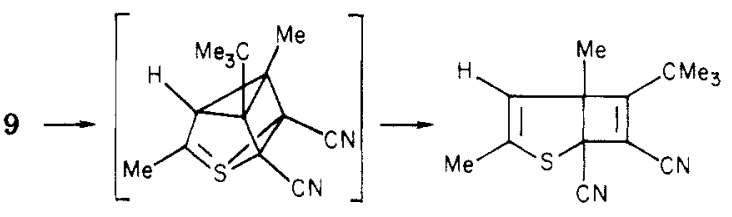

10

the 2- $\pi$-electron component in 1-3 is electron deficient and the four-electron component relatively electron rich, the predominant FMO contribution will be the combination of HOMO (four electron) and LUMO (two electron) as shown in I. For the reverse reactions, 4-6 $\rightarrow 1-3$, the

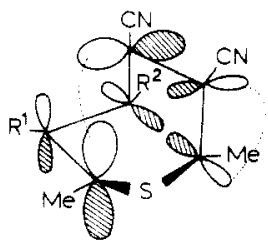

predominant interaction will be LUMO (four electron) and HOMO (2-electron) which is less favourable and this would explain the much faster rate of conversion of 1-3 $\rightarrow$ 4-6 than of the reverse antarafacial-antarafacial Cope rearrangement. In most of the photochemical rearrangements, compounds 1-3 follow the pathway that is reported for $2 a, 7 b$-dihydrocyclobuta $[b][1]$ benzothiophenes. ${ }^{10-13}$ Cleavage of the C-1,S bond and recombination of the diradical in a different mode accounts for the formation of 7-9 (Scheme II).

Prolonged irradiation of 3 or 9 gives a further isomer (10) which is possibly a daughter product of 9. A tentative mechanism is shown in Scheme II.

Our results show that cleavage of the C-1,C-5 carboncarbon bond in 2-thiabicyclo[3.2.0]hepta-3,6-diene-6,7dicarbonitriles $1-3$ is thermally possible. However, the products are not the desired thiepins but skeleton isomers of $1-\mathbf{3}$, because the rate of the symmetry-allowed $[3,3]$ sigmatropic reaction is faster than the symmetry-forbidden disrotatory ring opening of the 3,4-fused cyclobutenes. Photochemically the predominant reaction is cleavage of the C-1,S bond.

These results are very different from the work reported by Arnold and Hadjiantoniou. ${ }^{14}$ They prepared 5benzoyl-2-thiabicyclo[3.2.0]hepta-3,6-dienes by irradiation of 3-benzoylthiophenes in the presence of dimethyl acetylenedicarboxylate and report that the products are thermally unstable and eliminate sulfur rapidly to give mixtures of isomeric dimethyl phthalates and terephthalates. Unfortunately the initial products were not fully characterized, and only ${ }^{1} \mathrm{H}$ NMR data are published. It would mean that the benzoyl group at the 5-position

(31) Reference 30, p 113. must accelerate the ring opening of a fused cyclobutene enormously. To our knowledge such an effect is only known for dialkylamino substituents. ${ }^{10}$

On the other hand, Kuhn and Gollnick ${ }^{15,16}$ proposed that thiophene and 2,5-dimethylthiophene react photochemically with dimethyl acetylenedicarboxylate in a $[4+2]$ fashion via 7-thiabicyclo[2.2.1] hepta-2,5-dienes that spontaneously extrude sulfur at room temperature. The reactivity of 2-thiabicyclo[3.2.0] hepta-3,6-dienes at higher temperatures is the subject of the following paper. ${ }^{17}$

\section{Experimental Section}

See the preceding paper ${ }^{1}$ for general experimental information. A Karl Zeiss PMQ 11 spectrophotometer was used for the kinetic analyses by the ultraviolet method. Photochemical transformations were effected with a Hanau Hg medium-pressure TNN 15/32 lamp (254 nm).

Thermal Isomerizations. Compound $1(1 \mathrm{mmol})$ was heated for $18 \mathrm{~h}$ in $25 \mathrm{~mL}$ of dry, refluxing xylene. Removal of the solvent and repeated coevaporation with toluene and then hexane gave a solid which on recrystallization (pentane) gave 4 as colorless crystals: $82 \%$; $m p \quad 98-99^{\circ} \mathrm{C}$.

Compound 2 ( $1 \mathrm{mmol}$ ) was treated as described for 1 to give a solid which on recrystallization (pentane) gave 5 as colorless crystals: $84 \%$; $\mathrm{mp} 73-74^{\circ} \mathrm{C}$.

Compound 3 ( $1 \mathrm{mmol}$ ) was heated for $4 \mathrm{~h}$ in $25 \mathrm{~mL}$ of dry, refluxing toluene. Removal of the solvent and repeated coevaporations with hexane gave a solid which on recrystallization (pentane) gave 6 as colorless crystals: $83 \%$; mp $81-82^{\circ} \mathrm{C}$.

Kinetic Analysis by NMR Spectrometry. Method 1. Ten samples of $1(40 \mathrm{mg})$ in $0.4 \mathrm{~mL}$ of pentachloroethane or hexadeuteriodimethyl sulfoxide in sealed NMR tubes were placed in a thermostated bath. At regular intervals the samples were removed and immediately cooled. The samples were then analyzed by NMR spectrometry.

Method 2. Single samples of 1,2 , or 3 in the above solvents in sealed NMR tubes were placed in the heated probe of the NMR spectrometer. The spectra were recorded at regular intervals.

Kinetic Analysis by Ultraviolet Spectrometry. A solution of 1,2 , or $3(30-40 \mathrm{mg})$ was freshly prepared with $25 \mathrm{~mL}$ freshly distilled solvent (pentachloroethane, dimethyl sulfoxide, or 1,3,5-trimethylbenzene). Twelve 1.0-mL samples were pipetted into $10-\mathrm{mL}$ calibrated flasks. The 12 flasks were placed in a thermostated bath and removed at regular intervals. On removal, each flask was immediately cooled, the sample diluted to $10 \mathrm{~mL}$, and, as quickly as possible, the extinction coefficient measured at the absorption maximum for the charge-transfer transition of 1,2 , or 3. $(\lambda=402(1), 406(2)$, and $377 \mathrm{~nm}(3))$.

Kinetic Analysis by HPLC. Ten samples in sealed glass tubes, each containing $0.07 \mathrm{mmol}$ of $1,1.0 \mathrm{~mL}$ of pentachloroethane, and $0.81 \mathrm{mg}$ of naphthalene (as the internal standard), were placed in an oil bath of constant temperature. In equal intervals of $5 \mathrm{~min}$ the samples were cooled to $25^{\circ} \mathrm{C}$ and analyzed for their composition by HPLC (Lichrosorb Si 60-5 column) with benzene as the eluent. The rate constants were calculated from the standardized peak areas of 1,4 , and naphthalene.

Photochemical Isomerizations. A solution of 1 (1 mmol) in $400 \mathrm{~mL}$ of dry, deoxygenated ether $\left(\mathrm{N}_{2}\right)$ was irradiated with ultraviolet light at $-20^{\circ} \mathrm{C}$ for $8 \mathrm{~h}$. Removal of the solvent gave an oil which on multiple elution by thick-layer plate chromatography (hexane/ethyl acetate, 9:1) gave a solid. Recrystallization (pentane) gave 7 as colorless crystals: $67 \%$; $\mathrm{mp} 103-104^{\circ} \mathrm{C}$ (lit. ${ }^{2}$ mp 103.5-104 ${ }^{\circ} \mathrm{C}$ ).

Treatment of $2(1 \mathrm{mmol})$ as described for 1 gave a solid which on recrystallization (pentane) gave 8 as colorless crystals: $71 \%$; mp 93-94 ${ }^{\circ} \mathrm{C}$.

Treatment of $3(2 \mathrm{mmol})$ as described for 1 gave an oil which on column chromatography (hexane/ethyl acetate, 17:3) gave an oil which slowly solidified. Recrystallization (pentane) gave 10 as colorless crystals: $31 \% ; \mathrm{mp} 59-60^{\circ} \mathrm{C}$. Further elution gave 9 as a colorless oil, $42 \%$.

Irradiation of 3 , as described for 1 , but for only 1 h gave $9,74 \%$. Irradiation of 9, as described for 1 , for $8 \mathrm{~h}$ gave an approximately 1:1 mixture of 9 and 10 as shown by NMR spectroscopy. Further 
irradiation did not appear to affect this ratio substantially, but considerable darkening of the solution was observed.

Acknowledgment. We express our gratitude to Mr. $\mathrm{T}$. W. Stevens, Mrs. J. L. M. Klop-Vrielink, and Miss J. M.
Visser for recording spectral data.

Registry No. 1, 40321-00-4; 2, 80242-87-1; 3, 80242-88-2; 4, $37639-57-9 ; 5,80242-89-3 ; 6,80242-90-6 ; 7,80242-91-7 ; 8,80242-94-0$; 9, 80242-92-8; 10, 80242-93-9.

\title{
2-Thiabicyclo[3.2.0]hepta-3,6-dienes. 3. Desulfuration and Sulfuration of 2-Thiabicyclo[3.2.0]hepta-3,6-dienes and X-ray Crystal Structure of 3a,6,7,8,9,9a-Hexahydro-3a,5-dimethylthieno[3,2-b ][2]benzothiophene-2,3-di- carbonitrile
}

\author{
Richard H. Hall, ${ }^{\dagger}$ Herman J. den Hertog, Jr., ${ }^{\dagger}$ David N. Reinhoudt, ${ }^{\dagger \dagger}$ Sybolt Harkema, ${ }^{\ddagger}$ \\ Gerrit J. van Hummel, ${ }^{\ddagger}$ and Jos W. H. M. Uiterwijk \\ Departments of Organic Chemistry and Chemical Physics, Twente University of Technology, \\ Enschede, The Netherlands
}

Received June 30, 1981

\begin{abstract}
The 2-thiabicyclo[3.2.0] hepta-3,6-dienes 1-7 extrude sulfur in solution at $285^{\circ} \mathrm{C}$ to give the 1,2-benzenedicarbonitriles 8-12 in yields of 42-56\%. 5-(1,1-Dimethylethyl)-3,6-dimethyl-2-thiabicyclo[3.2.0]hepta-3,6-diene-1,7-dicarbonitrile (6) reacts at $140^{\circ} \mathrm{C}$ to give a mixture of the Cope-rearranged isomer 13, the $1,2-$ benzenedicarbonitrile 11 , and possibly a 3a,6a-dihydrothieno[3,2-b]thiophene (14). Reaction of $2 a, 5,6,7,8,8 a-$ hexahydro-2a,4-dimethylbenzo[c]cyclobuta[b]thiophene-1,2-dicarbonitrile $(15)$ at $140{ }^{\circ} \mathrm{C}$ gives a mixture of desulfurated (16) and sulfurated (17) products in yields of $88 \%$ and $70 \%$, respectively. Single-crystal X-ray analysis proved the $3 a, 6,7,8,9,9 a$-hexahydrothieno[3,2-b][2]benzothiophene structure (17). The possible mechanism of the insertion of sulfur in the carbon-carbon single bond of $\mathbf{1 5}$ is discussed.
\end{abstract}

The two preceding papers in this series ${ }^{1,2}$ describe the preparation $^{1}$ of 2-thiabicyclo[3.2.0]hepta-3,6-diene-6,7dicarbonitriles and their thermal $\left(120-140^{\circ} \mathrm{C}\right)^{2}$ and photochemical ${ }^{2}$ isomerization to the analogous 4,5- (1-3) and 1,7-dicarbonitriles (4-7), respectively. Since the two modes of isomerization did not lead to the desired thiepins, ${ }^{1,2}$ it was decided to investigate the effect of higher temperatures on the 4,5- and 1,7-dicarbonitriles as a possible route to thiepins.

Further, it was considered that the 1,2-dicarbonitrile (15), ${ }^{1}$ which cannot undergo photochemical isomerization by the described ${ }^{2}$ mechanism and which is unlikely, because of the bridging, to undergo the Cope rearrangement ${ }^{2}$ (thermal isomerization at moderate temperature), would undergo facile $\mathrm{C}-2 \mathrm{a}, \mathrm{C}-8 \mathrm{a}$ cleavage on heating and result in thiepin formation.

Two factors make it difficult to predict the temperatures required for ring opening of the cis-fused cyclobutene ring in 1-7 and 15. Comparison with the reactivity of other cis-fused cyclobutenes indicates that both increased strain and participation of the $\pi$ electrons of the vinyl group will lower the activation energy. ${ }^{3,4}$ Frey et al..$^{5}$ found that the isomerization of bicyclo[3.2.0]hept-6-ene to cyclohepta1,3-diene has an activation energy of $190.4 \mathrm{~kJ} \mathrm{~mol}^{-1} \mathrm{com}$ pared with a value of $143.9 \mathrm{~kJ} \mathrm{~mol}^{-1}$ for cis-3,4-dimethylcyclobutene. ${ }^{3}$ However, the activation energy of the isomerization of bicyclo[3.2.0]hepta-3,6-diene to cycloheptatriene has an activation energy of only $165.3 \mathrm{~kJ}$ $\mathrm{mol}^{-1}{ }^{6}$ An allylic stabilization of an intermediate biradical or of a biradicaloid transition state in the symmetry-forbidden disrotatory ring opening has been postulated to account for this difference. ${ }^{6}$ To our knowledge, there is no information available as to how a sulfur or a thiovinyl substituent at the 3-position of cyclobutenes effects the

\footnotetext{
${ }^{\dagger}$ Department of Organic Chemistry.

${ }^{\ddagger}$ Department of Chemical Physics.
}

Chart I

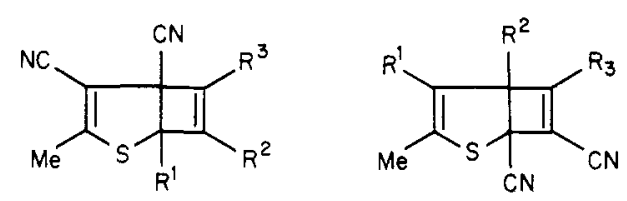

$1, R^{1}=R^{2}=R^{3}=M e \quad 4, R^{1}=R^{2}=R^{3}=M e$

$2, R^{1}=\mathrm{Me} ; R^{2}=\mathrm{CMe}_{3} ; 5, \mathrm{R}^{1}=\mathrm{CMe}_{3} ; \mathrm{R}^{2}=\mathrm{H}$; $\mathrm{R}^{3}=\mathrm{H}$

$R^{3}=M e$

$3, \mathrm{R}^{1}=\mathrm{Me} ; \mathrm{R}^{2}=\mathrm{H} ; \quad 6, \mathrm{R}^{1}=\mathrm{H} ; \mathrm{R}^{2}=\mathrm{CMe}_{3}$; $\mathrm{R}^{3}=\mathrm{CMe}_{3}$

$7, R^{1}=H ; R^{2}=M e ;$ $\mathrm{R}^{3}=\mathrm{CMe}_{3}$<smiles>[R]c1c([R])c(C#N)c(C#N)c([R])c1[13CH]</smiles>

$8, R^{1}=R^{2}=R^{3}=M e$

9, $\mathrm{R}^{1}=\mathrm{Me} ; \mathrm{R}^{2}=\mathrm{CMe}_{3}$; $R^{3}=H$

$10, R^{1}=\mathrm{Me} ; \mathrm{R}^{2}=\mathrm{H}$; $\mathrm{R}^{3}=\mathrm{CMe}_{3}$

$11, \mathrm{R}^{1}=\mathrm{CMe}_{3} ; \mathbf{R}^{2}=\mathrm{H}$; $\mathrm{R}^{3}=\mathrm{Me}$

$12, \mathrm{R}^{1}=\mathrm{H} ; \mathrm{R}^{2}=\mathrm{Me}$; $\mathrm{R}^{3}=\mathrm{CMe}_{3}$

rate of isomerization. Another unpredictable factor is the influence of cyano groups in compounds 1-7 and 15 be-

(1) Part 1: Hall, R. H.; den Hertog, H. J., Jr.; Reinhoudt, D. N. J. Org. Chem., accompanying paper in this issue.

(2) Part 2: Hall, R. H.; den Hertog, H. J., Jr.; Reinhoudt, D. N. J. Org. Chem., accompanying paper in this issue.

(3) Frey, H. M.; Walsh, R. Chem. Rev. 1969, 69, 103.

(4) Curry, M. J.; Stevens, I. D. R. J. Chem. Soc., Perkin Trans. 21980 , 